\title{
Full-term, peri-urban South African infants under 6 months of age are at risk for early-onset anaemia
}

\author{
LN Sibeko ${ }^{1}$, MA Dhansay ${ }^{2}$, KE Charlton ${ }^{3}$, T Johns $^{1}$, ME Van Stuijvenberg ${ }^{2}$ and \\ K Gray-Donald ${ }^{1, *}$ \\ 'School of Dietetics and Human Nutrition, McGill University, 21111 Lakeshore Road, Ste Anne de Bellevue, \\ Montreal, Quebec, Canada, H9X 3V9: ' ${ }^{2}$ Nutrition Intervention Research Unit, Medical Research Council, Tygerberg, \\ South Africa: ${ }^{3}$ Nutrition \& Dietetics Division, School of Health and Rehabilitation, Faculty of Medicine, \\ University of Cape Town and Chronic Diseases of Lifestyles Unit, Medical Research Council, Parow, South Africa
}

Submitted 20 August 2003: Accepted 5 February 2004

\begin{abstract}
Objective: There is a paucity of data on the micronutrient status of low-income, lactating South African women and their infants under 6 months of age. The aim of this study was to elucidate the level of anaemia and vitamin A deficiency (VAD) in peri-urban breast-feeding women and their young infants.

Design: Cross-sectional study including anthropometric, biochemical and infant feeding data.

Setting: Peri-urban settlement in Cape Town, South Africa.

Subjects: Breast-feeding women $(n=113)$ and their infants (aged 1-6 months) attending a peri-urban clinic.

Results: Mean (standard deviation (SD)) haemoglobin (Hb) of the lactating mothers was 12.4 (1.3) $\mathrm{g} \mathrm{dl}^{-1}$, with $32 \%$ found to be anaemic $\left(\mathrm{Hb}<12 \mathrm{~g} \mathrm{dl}^{-1}\right)$. Maternal serum retinol was 49.8 (SD 13.3) $\mu \mathrm{g} \mathrm{dl}^{-1}$, with $4.5 \%$ VAD. Using breast milk, mean (SD) retinol concentration was found to be 70.6 (24.6) $\mu \mathrm{g} \mathrm{dl}^{-1}$ and 15.7 (8.3) $\mu \mathrm{g} / \mathrm{g}$ milk fat, with $13 \%$ below the cut-off level of $<8 \mu \mathrm{g} / \mathrm{g}$ fat. There was no correlation found between breast milk retinol and infant serum retinol. $Z$-scores (SD) of height-for-age, weight-for-age and weight-for-height were -0.69 (0.81), 0.89 (1.01) and 1.78 (0.83), respectively. Mean (SD) infant $\mathrm{Hb}$ was 10.9 (1.1) $\mathrm{g} \mathrm{dl}^{-1}$, with the prevalence of anaemia being 50\%, 33\% and 12\% using Hb cut-offs below $11 \mathrm{~g} \mathrm{dl}^{-1}, 10.5 \mathrm{~g} \mathrm{dl}^{-1}$ and $9.5 \mathrm{~g} \mathrm{dl}^{-1}$, respectively. Mean (SD) infant serum retinol was 26.9 (7.2) $\mu \mathrm{g} \mathrm{dl}^{-1}$, with $10 \%$ being VAD. None of the infants was exclusively breast-fed, 22\% were predominantly breast-fed and $78 \%$ received complementary (mixed) breast-feeding. Thirty-two per cent of infants received weaning foods at an exceptionally young age ( $\leq 1$ month old).

Conclusion: A high rate of anaemia is present in lactating women residing in resourcepoor settings. Moreover, their seemingly healthy infants under 6 months of age are at an elevated risk of developing early-onset anaemia and at lower risk of VAD.
\end{abstract}

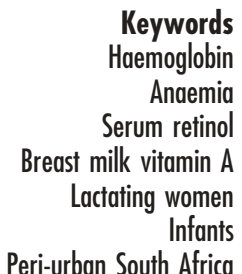

Peri-urban South Africa
Globally, more than 2 billion people are deficient in one or more micronutrients, with both vitamin A deficiency (VAD) and iron-deficiency anaemia (IDA) prevalent in much of the developing world ${ }^{1}$. Combined, these two micronutrient deficiencies contribute to the serious burden of disease in many areas of the world and consequently are declared public health problems of great enormity ${ }^{2}$.

Iron deficiency is recognised as the primary, although not the only cause of anaemia ${ }^{3}$. The consequences of IDA include impaired cognitive development and psychomotor function in infants and children ${ }^{4,5}$, a decrease in work productivity, and increased maternal and child mortality in cases of severe anaemia ${ }^{6}$. South African data indicate that one child in 10 is iron-deficient and one in 20 has IDA, the most vulnerable group being children in the 6 to 23 months age group ${ }^{7}$. However, little is known about the status of infants under 6 months of age.

Sub-clinical VAD has been shown to increase the risk of infections, a major contributor to the morbidity and mortality of deficient children ${ }^{8}$. In South Africa, a third of pre-school aged children have been identified as having sub-clinical VAD, indicating that, by World Health Organization (WHO) criteria', South Africa has a serious public health problem of VAD.

Breast-feeding is considered protective of both vitamin A and iron status in infants under 6 months of age. The high bioavailability of iron in breast milk ${ }^{10}$, combined with the infant's own stores, protects the infant's iron status in 
those initial months of life. Human milk also provides the infant with a rich source of retinol through both colostrum and mature breast milk ${ }^{11,12}$. However, it is not clear if anaemia and marginal VAD exist in young breast-fed infants from vulnerable, disadvantaged backgrounds.

Although breast-feeding rates are high in the South African population ${ }^{13}$, the early introduction of complementary 'weaning' foods is a common practice among breast-feeding women ${ }^{14-17}$. Such feeding practices may impose a negative influence on the vitamin A and iron status of the breast-fed infant during a period of high nutrient needs for development.

Given the cultural value of breast-feeding in the African population and the relationship between breast milk, iron and vitamin A status and maternal and child health, this study was undertaken to investigate the prevalence of anaemia and VAD, and the breast-feeding patterns, of lactating women and their infants below 6 months of age from a peri-urban settlement of Cape Town.

\section{Subjects and methods}

\section{Study area}

The study took place in the community of Langa, one of many settlements situated on the periphery of Cape Town, South Africa. Langa is one of the oldest 'townships' (settled in 1933), with a population of $46505^{18}$. Dwellings in this community range from formal homes to informal squatter camps.

\section{Study design and subjects}

This cross-sectional study of women and their infants attending a community health clinic, for a variety of health reasons, was conducted between August and November 2000. All mothers were approached, with infants being eligible if they were aged between 1 and 6 months, had a birth weight $\geq 2500 \mathrm{~g}$ (both criteria confirmed by the infant's Road To Health Card; documentation recorded by health personnel at the time of infant birth), were still being breast-fed, and had no current illness or history of being sick in the past two weeks (mother questioned plus clinical examination performed by a paediatrician). Both mother and infant were excluded if either had received any vitamin/mineral supplements during the postpartum period. Once the study was clearly explained to the mother in Xhosa (local language), informed signed consent was obtained for participation of both the mother and infant.

Of the 137 women initially asked to participate in the study, nine declined participation (mothers feared distressing their infants) and 11 mother and infant pairs were discharged from the study due to our inability to draw venous blood from the infants. Additionally, two infants were discharged because one was febrile and the other suspected of HIV infection, with both infants referred for immediate follow-up. Participating in the study were 115 mothers and 117 infants, including two sets of twins; data analysis, however, was limited to singletons and their mothers ( $n=113$ for both).

Ethical approval for the study was obtained from the Research Ethics Committees of McGill University in Canada and the University of Cape Town in South Africa.

\section{Collection and analysis of blood samples}

Non-fasting blood samples from mothers $(10 \mathrm{ml})$ and infants $(5 \mathrm{ml})$ were drawn by venepuncture into two vacutainer tubes per mother and infant; one tube containing ethylenediaminetetraacetic acid for determination of full blood count (FBC) and the other for determining the serum retinol levels. Infant blood draws were conducted by a paediatrician, while the maternal blood collection was performed by a qualified nurse. The specimens for serum retinol measurement were protected from light and stored immediately on ice. They were transported within $5 \mathrm{~h}$ of collection to the Medical Research Council (MRC) and stored at $-20^{\circ} \mathrm{C}$ for determination of serum retinol using high-performance liquid chromatography (HPLC) following the method of Catignani and Bieri ${ }^{19}$. The Haematology Department at Groote Schuur Hospital undertook the FBC determination on the same day. Using $\mathrm{H}^{*} 1$ and Advia 120 (Bayer) instrument, FBC analysis included: haemoglobin ( $\mathrm{Hb})$, haematocrit and mean corpuscular volume (MCV).

\section{Collection and analysis of breast milk samples}

All lactating mothers were asked to express breast milk (approximately $30 \mathrm{ml}$ ) into sterile plastic containers with lids. Given the choice between a breast pump and manual expression, all subjects chose manual expression. As vitamin A is located in milk fat, vitamin A content is dependent on the fat content of the breast milk sample. However, milk fat is sensitive to sampling variation. Therefore the casual sampling method $^{9}$ was used to control for this. Once collected, breast milk samples were immediately placed on ice in a portable cooler with a cover and transported, within $5 \mathrm{~h}$ of expression, to the MRC laboratory. Prior to freezing, the breast milk sample was re-homogenised and the fat content determined according to the creamatocrit method described by Lucas et $a l^{20}$. The sample was then aliquoted and frozen at $-20^{\circ} \mathrm{C}$ until analysed. Vitamin A content was determined by HPLC based on the method of Strobel et al. ${ }^{21}$.

\section{Anthropometric measurements}

Body weights were measured using an A\&D Precision Health Scale UC-300 (Tokyo, Japan). Infants were weighed without clothing (dry diaper only) using an indirect method and the mothers were weighed directly without shoes or coat/sweater. All weights were measured in triplicate to the nearest $0.1 \mathrm{~kg}$. Supine infant lengths were measured using a measuring board placed on a flat surface, with a fixed headboard and a 
moveable foot-board. Two people conducted the measurement, one positioning the head and the other the feet. Measurement was done to the nearest $0.1 \mathrm{~cm}$ in triplicate. The mother's height was measured (without shoes) to the nearest $0.1 \mathrm{~cm}$ in triplicate using a measure ( $2 \mathrm{~m}$ Panamedic) with a sliding headpiece, attached to the wall.

Anthropometric indices for assessing infant growth were $Z$-scores (using the reference population from the National Center for Health Statistics) for height-for-age (HAZ), weight-for-height (WHZ) and weight-for-age (WAZ). For the mothers, body mass index (BMI; $\mathrm{kg} \mathrm{m}^{-2}$ ) was used.

\section{Questionnaire}

A trained fieldworker interviewed the mothers in Xhosa using a field-tested questionnaire. Mothers choosing to complete the survey in English were interviewed by the principal investigator (L.S.). The structured questionnaire was adapted from the data collection guidelines developed by $\mathrm{WHO}^{22}$ for breast-feeding research and designed to elicit information on sociodemographic variables, infant feeding behaviour and breast-feeding beliefs, attitudes and practices. Mothers participating in our study were asked to describe their breast-feeding behaviours as well as their general infant feeding practices. $\mathrm{WHO}^{23}$ breastfeeding categories were used to classify infants according to the pattern of breast-feeding followed: exclusive breastfeeding (breast milk only, nothing else not even water), predominant breast-feeding (mostly breast milk plus small amounts of non-nutrient liquids) and complementary breast-feeding (breast milk in addition to other foods and/or liquids). The complementary breast-fed group was broken down further into three subgroups: (1) breast milk plus solid food $(\mathrm{BM}+\mathrm{S})$; (2) breast milk plus solid food and breast milk substitute $(\mathrm{BM}+\mathrm{S}+\mathrm{Subs})$; and (3) breast milk plus breast milk substitute $(\mathrm{BM}+\mathrm{Subs})$.

\section{Statistical analysis}

Data were analysed using the SAS system for Windows, version 8.0 (SAS Institute Inc., Cary, NC, USA). Epi-Info version 2000 (Centers for Disease Control and Prevention, Atlanta, GA, USA) was used to calculate the $Z$-scores for growth of the infants. Values for haemoglobin, serum retinol and breast milk vitamin A were all normally distributed. Pearson correlation was used to examine associations between variables. Correlates of infant indicators of micronutrient levels (haemoglobin, serum retinol and breast milk vitamin A concentration) were analysed using multiple linear regression. Differences between means were analysed using Student's $t$-test, while the chi-square test was employed to examine differences between proportions. Results were considered significant at $P<0.05$.

\section{Results}

Participating mothers' ages ranged from 15 to 43 years (mean 26 years), with almost half being primiparous (Table 1). The mean maternal BMI was high at $28.6 \mathrm{~kg} \mathrm{~m}^{-2}$ and was higher among older mothers $(P<0.001)$, as well as among those with higher parity $(P<0.001)$. Unemployment was very high $(81 \%)$ in this population despite the fact that $97 \%$ of the mothers reported having some level of schooling, with $24 \%$ having completed high school education.

The majority (62\%) of the infants were under 3 months of age when examined. Infant anthropometric data indicated a mean (standard deviation (SD)) HAZ of -0.69 (0.81), with only two (1.8\%) infants having scores $<-2 \mathrm{SD}$. In general, these were large but short babies with positive means found for both WAZ $(0.89$ (1.01)) and WHZ (1.78 (0.83)), further evidenced by $12 \%$ and $35 \%$ of the infants having WAZ and WHZ values $>2 \mathrm{SD}$, respectively. There were no associations found between infant anthropometric values and infant or maternal micronutrient measurements.

Using the $\mathrm{Hb}$ cut-off value of $<12 \mathrm{~g} \mathrm{dl}^{-1}\left(120 \mathrm{~g} \mathrm{l}^{-1}\right)$ for lactating women, $32 \%$ of the mothers were found to be anaemic with a mean $\mathrm{Hb}$ concentration of $12.4 \mathrm{~g} \mathrm{dl}^{-1}$ $\left(124 \mathrm{gl}^{-1}\right.$ ) (Table 2$)$. However, only $13 \%$ had low MCV $(<80 \mathrm{fl})$ values and $20 \%$ had low haematocrit $(<36 \%)$ levels.

Mean infant $\mathrm{Hb}$ concentration was $10.9 \mathrm{~g} \mathrm{dl}^{-1}$ $\left(109 \mathrm{gl}^{-1}\right)$, with the prevalence of anaemia being $50 \%$, $33 \%$ and $12 \%$ using $\mathrm{Hb}$ cut-off values of $11 \mathrm{~g} \mathrm{dl}^{-1}$ $\left(110 \mathrm{gl}^{-1}\right), 10.5 \mathrm{~g} \mathrm{dl}^{-1}\left(105 \mathrm{gl}^{-1}\right)$ and $9.5 \mathrm{~g} \mathrm{dl}^{-1}\left(95 \mathrm{gl}^{-1}\right)$, respectively. There was no statistically significant difference between the mean $\mathrm{Hb}$ concentration of infants younger and older than 3 months of age (Table 2). Low

Table 1 Characteristics of lactating mothers and their 1 - to 6month-old infants from a peri-urban community of Cape Town (Langa). Values are expressed as mean (SD) [minimum-maximum] or as \%

\begin{tabular}{|c|c|}
\hline Characteristic & Value \\
\hline \multicolumn{2}{|l|}{ Mothers $(n=115)$} \\
\hline $\mathrm{Age}^{*}$ (years) & $26(6.25)[15-43]$ \\
\hline $\mathrm{BMI}^{*}\left(\mathrm{~kg} \mathrm{~m}^{-2}\right)$ & $28.6(5.09)[18.1-46.1]$ \\
\hline Primiparous & 48 \\
\hline Unemployment & 81 \\
\hline Education (completed high school) & 24 \\
\hline \multicolumn{2}{|l|}{ Infants $(n=113)$} \\
\hline Gender (male) & 51 \\
\hline Age (months) & $2.79(1.32)$ \\
\hline $1-3$ months & 62 \\
\hline$>3-6$ months & 38 \\
\hline Birth weight (g) & 3216 (390.5) [2500-4400] \\
\hline Weight $(\mathrm{kg})$ & $6.2(1.3)[3.9-10.4]$ \\
\hline Length $(\mathrm{cm})$ & $57.7(4.1)[49.9-69.2]$ \\
\hline Vaginal birth & 76 \\
\hline MOU/hospital birth & 98 \\
\hline
\end{tabular}

SD - standard deviation; BMI - body mass index; MOU - midwife and obstetric unit.

${ }^{*} n=113$ for age and $n=114$ for $\mathrm{BMI}$ due to missing data. 
Table 2 Haematological and serum retinol profiles of lactating mothers and their 1 - to 6 -month-old infants

\begin{tabular}{|c|c|c|c|c|c|}
\hline \multirow[b]{3}{*}{ Biochemical index } & \multirow{2}{*}{\multicolumn{2}{|c|}{ Mothers $(n=110)$}} & \multicolumn{3}{|c|}{ Infants $(n=104)$} \\
\hline & & & \multicolumn{2}{|c|}{ Mean (SD) } & \multirow[b]{2}{*}{$\begin{array}{c}\text { Percentage } \\
\text { below cut-off (cut-off) }\end{array}$} \\
\hline & Mean (SD) & $\begin{array}{c}\text { Percentage } \\
\text { below cut-off (cut-off) }\end{array}$ & $\begin{array}{l}\leq 3 \text { months } \\
\text { old }(n=70)\end{array}$ & $\begin{array}{l}>3 \text { months } \\
\text { old }(n=34)\end{array}$ & \\
\hline Serum retinol $\left(\mu \mathrm{g} \mathrm{dl}^{-1}\right)$ & $49.8(13.3) \dagger$ & $4.5\left(<30 \mu \mathrm{g} \mathrm{dl}^{-1}\right)$ & $24.8(6.4) \ddagger$ & $30.1(7.1)^{*}$ & $10\left(<20 \mu \mathrm{g} \mathrm{dl}^{-1}\right)$ \\
\hline Breast milk vitamin A ( $\mu \mathrm{g} / \mathrm{g}$ fat) & $15.7(8.3) \S$ & $13(<8 \mu \mathrm{g} / \mathrm{g})$ & $-10+1+$ & - & - \\
\hline $\mathrm{Hb}\left(\mathrm{adl}^{-1}\right)$ & $12.4(1.3)$ & $32\left(<12 \mathrm{qdl}^{-1}\right)$ & $10.8(1.1)$ & $11.1(1.1)$ & $50\left(<11 \mathrm{gdl}^{-1}\right)$ \\
\hline $\operatorname{MCV}(f \mid)$ & $86.6(6.3)$ & $13(<80 \mathrm{fl})$ & $90.5(6.6)$ & $80.4(5.28)^{*}$ & $2.8(<73 \mathrm{fl})$ \\
\hline $\mathrm{Ht}(\%)$ & $38(0.04)$ & $20(<36 \%)$ & $33(0.03)$ & $34(0.03)$ & $37(<37 \%)$ \\
\hline
\end{tabular}

$\mathrm{SD}$ - standard deviation; $\mathrm{Hb}$ - haemoglobin; MCV - mean corpuscular volume; $\mathrm{Ht}$ - haematocrit.

$\dagger n=112$.

$\ddagger n=110$ ( $n=73$ for $\leq 3$ months old, $n=37$ for $>3$ months old).

$\S n=100$.

${ }^{*}$ Significantly different, $P<0.001$ ( $\leq 3$ months old vs. $>3$ months old).

haematocrit $(<33 \%)$ levels were found in $37 \%$ of the infants, while $2.8 \%$ (three babies) had low MCV $(<73 \mathrm{fl})$ values. Distributions of $\mathrm{Hb}$ values for mothers and infants are shown in Figs $1 \mathrm{a}$ and $1 \mathrm{~b}$, respectively.

Mean (SD) serum retinol for the lactating mothers was 49.8 (13.3) $\mathrm{g} \mathrm{dl}^{-1}\left(1.74 \mu \mathrm{moll}^{-1}\right)$ (Table 2), with $4.5 \%$ found to be below the cut-off level of $<30.0 \mu \mathrm{g} \mathrm{dl}^{-1}$ $\left(1.05 \mathrm{mmoll}^{-1}\right)$. Only one mother had a value below $<20 \mu \mathrm{g} \mathrm{dl}^{-1}\left(0.70 \mu \mathrm{mol}{ }^{-1}\right)$. Mean (SD) retinol concentration in breast milk was 70.6 (24.6) $\mu \mathrm{g} \mathrm{dl}^{-1}$ $\left(2.46 \mu \mathrm{moll}^{-1}\right)$. Adjustment to account for the fat content

a)

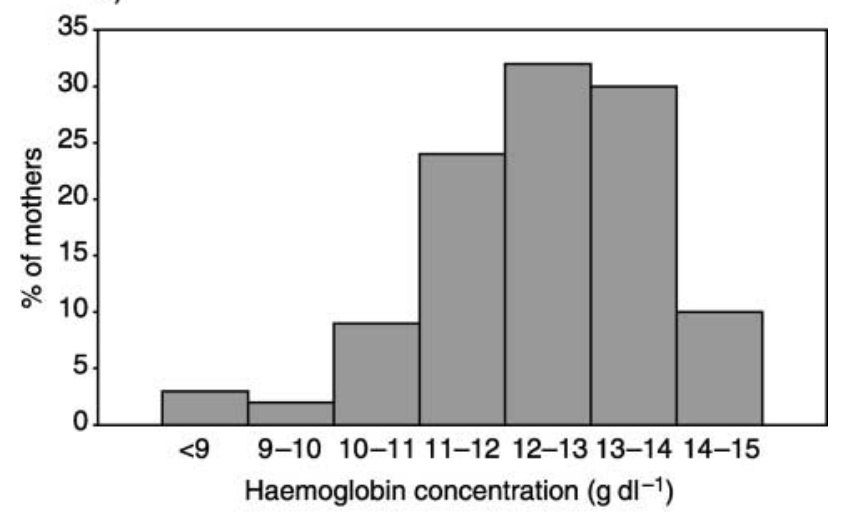

b)

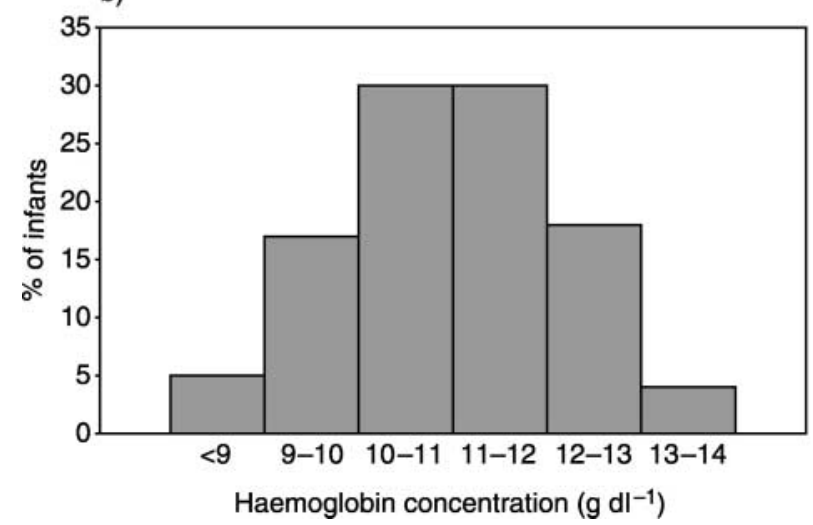

Fig. 1 Distribution of haemoglobin values for (a) mothers and (b) infants in human milk (using creamatocrit data) resulted in a breast milk fat retinol mean of $15.7 \mu \mathrm{g} / \mathrm{g}$ fat, with $13.3 \%$ of the mothers having breast milk fat retinol values below the cut-off value of $8 \mu \mathrm{g} / \mathrm{g}$ fat.

The infants had a mean serum retinol of $26.9 \mu \mathrm{g} \mathrm{dl}^{-1}$ $\left(0.94 \mu \mathrm{moll}^{-1}\right)$, with $10 \%(11 / 110)$ and $3.6 \%$ (4/110) of infants having values below $20 \mu \mathrm{g} \mathrm{dl}^{-1}$ and $15 \mu \mathrm{g} \mathrm{dl}^{-1}$, respectively. The mean serum retinol concentrations for infants aged 1-3 months were significantly lower $(P<0.001)$ than for children aged 3-6 months (Table 2). There was no significant correlation found between breast milk vitamin A concentration and infant serum retinol. The frequency distributions of serum retinol concentrations for both the lactating mothers and their infants are illustrated in Figs $2 \mathrm{a}$ and 2b, respectively.

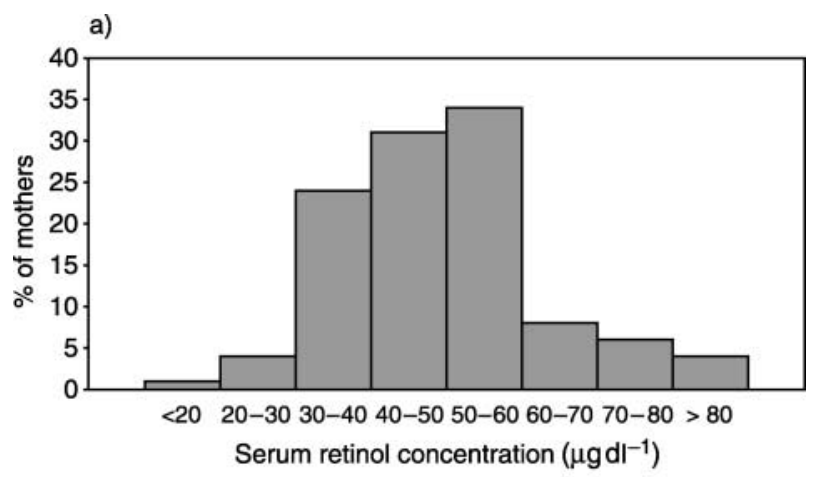

b)

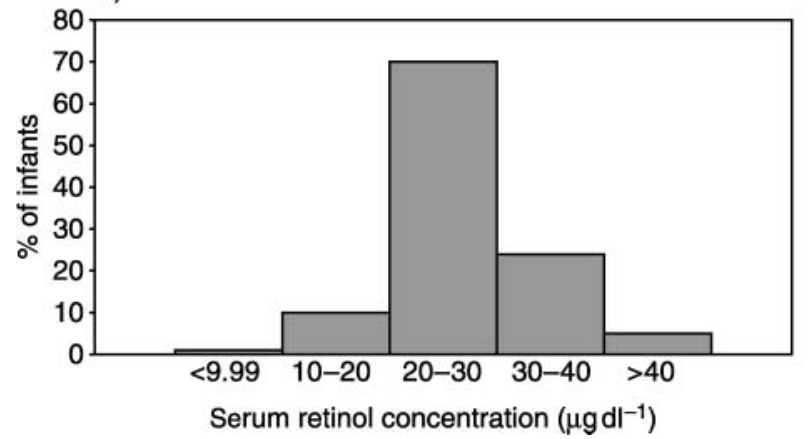

Fig. 2 Distribution of serum retinol values for (a) mothers and (b) infants 
There was no correlation between maternal and infant $\mathrm{Hb}$ levels, or between maternal and infant retinol levels. However, a correlation of $r=0.32$ between maternal and infant MCV values $(P=0.001)$ was observed. Examination of the independent variables associated with infant micronutrient concentrations indicated a positive relationship between infant serum retinol and infant age, weight and length $(P<0.001)$ as determined by linear regression models. However, multiple regression analysis with serum retinol as the dependent variable indicated only length but not age was significant (weight correlated with length and therefore was not entered into the model).

Since there were no exclusively breast-fed infants found in the entire sample of infants, responses from mothers describing their breast-feeding practices were categorised into predominant and complementary breast-feeding $(\mathrm{BM}+\mathrm{S}, \mathrm{BM}+\mathrm{S}+\mathrm{Subs}$ and $\mathrm{BM}+\mathrm{Subs})$, with $22 \%$ of the infants being predominant breast-feeders while $78 \%$ were complementary breast-fed. Infant foods were introduced at $\leq 1$ month of age to $32 \%$ of the infants. Of the mothers feeding infants weaning foods (65\%), 96\% cited commercial infant cereal as the solid food of choice, with the remainder reporting that they gave a home-made, maize-based gruel. The breast milk substitutes offered to infants were iron-fortified, but some mothers reported using UHT (ultra high temperature) pasteurised cow's milk when they ran out of breast milk substitutes. In some cases, breast milk substitute was used to mix with infant cereal rather than fed directly to the infant. Water and, in some cases, the liquid from a traditional maize dish ( $\operatorname{samp}$ and beans) were the only other fluids reported as being offered to the infants. In the predominant breast-feeding group, all of the mothers reported water as the fluid given to infants. Mean $\mathrm{Hb}$ values were not significantly different among feeding groups and as age was not related to $\mathrm{Hb}$, age did not act as a confounder in this comparison. Among the 11 infants with marginal VAD, four were predominant breast-feeders and two, four and one received $\mathrm{BM}+\mathrm{S}$, $\mathrm{BM}+\mathrm{S}+$ Subs and $\mathrm{BM}+$ Subs, respectively. There was no difference in serum retinol by feeding type.

A comparison of the percentage of infants below and above 3 months of age in predominant versus complementary feeders indicated that a significant difference $(P<0.001)$ existed between feeding category and infant age (Table 3$)$.

\section{Discussion}

As little is known about the micronutrient status of poor, lactating women and their infants under 6 months of age in the South African population ${ }^{24}$, we examined the haemoglobin and retinol profile of this group within a South African peri-urban setting (Langa) in the Western Cape.

Infant anthropometric data did not indicate stunting, wasting or underweight in our group of subjects. Lowbirth-weight infants were excluded from the study, which
Table 3 Proportion (\%) of infants within each breast-feeding category by infant age

\begin{tabular}{lcc}
\hline Breast-feeding category & $\begin{array}{c}1-3 \text { months } \\
(n=72)\end{array}$ & $\begin{array}{c}>3-6 \text { months } \\
(n=45)\end{array}$ \\
\hline Exclusive breast-feeding & 0 & 0 \\
Predominant breast-feeding & 33 & $2^{*}$ \\
Complementary breast-feeding & 67 & 98 \\
\hline
\end{tabular}

Predominant breast-feeding - mostly breast milk plus non-nutritive fluids; complementary breast-feeding - breast milk plus food and/or fluids including breast milk substitutes.

*Differences between predominant and complementary breast-feeding were significant (chi-square test).

would certainly have influenced the anthropometric results. A fair proportion (12\% WAZ and 35\% WHZ) of the infants had $Z$-scores above 2SD. Given that this population of children was breast-fed, we suggest that breast-feeding contributed to the dietary adequacy that protected these infants from signs of acute malnutrition at this stage of their development. With the exception of a direct association between serum retinol and infant length, we did not find any other association between haemoglobin, vitamin A and infant anthropometry scores, a finding that is similar to Dijkhuizen et al.'s ${ }^{25}$ study of the micronutrient status of breast-fed infants.

Iron deficiency is believed to be the most common cause of anaemia, particularly in areas where anaemia is prevalent $^{26}$; therefore haemoglobin concentration is considered an acceptable and valuable measure for assessing IDA, particularly in the field setting ${ }^{27}$. Employing the universal cut-off standards of $\mathrm{Hb}$ concentrations for lactating mothers $\left(<12 \mathrm{~g} \mathrm{dl}^{-1}\right)$ and young infants $\left(<11 \mathrm{~g} \mathrm{dl}^{-1}\right)^{28}$, we found mild anaemia to be prevalent in our population of breast-feeding mothers (32\%) and their infants (50\%). Haemoglobin distribution (Fig. 1a) indicates that most of the mothers' Hb levels fell within the relatively healthy range of 11 to $13.5 \mathrm{~g} \mathrm{dl}^{-1}$. Of great concern was the high prevalence of early-onset anaemia evident in the infants, with a third having $\mathrm{Hb}$ values below $10.5 \mathrm{~g} \mathrm{dl}^{-1}$ (reference 29). In their study of Western Cape low-income infants aged 1-12 months, Kirsten et al. ${ }^{30}$ found $17.5 \%$ of the infants to be anaemic (using the cut-off of $10 \mathrm{~g} \mathrm{dl}^{-1}$ for infants aged 3 months and above). When the anaemia criterion level was raised by $1 \mathrm{~g} \mathrm{dl}^{-1}, 57.5 \%$ of the infants were found to be anaemic, a value closer to our prevalence of 50\%. Not only did their study and our work find similar mean infant $\mathrm{Hb}$ concentrations (11 vs. $10.9 \mathrm{~g} \mathrm{dl}^{-1}$ ), but both investigations also report a high rate of anaemia in very young, seemingly healthy infants. It is important to note that, unlike our study population, the majority of infants in Kirsten et al.'s ${ }^{30}$ study were not breast-fed after 6 weeks of age.

Clearly, many factors can contribute to anaemia in the young infant, such as the infant's perinatal history. A study of Guatemalan infants found that infants with delayed cord clamping had significantly higher haemoglobin concentrations than those with early clamping ${ }^{31}$, but not 
all studies show this relationship ${ }^{32}$. Also, some of the infants in our study may have been born with poor iron stores. However, there seems to be an indication that it is improbable for infants to have depleted iron stores unless their mothers have IDA, particularly during pregnancy ${ }^{33}$. Although we found no relationship between birth weight or current weight and haemoglobin concentration, infants in our study were on the heavy side and thus it can be assumed that rapid weight gain took place, a factor that contributes to the depletion of iron stores as shown in a recent study of breast-fed Ghanaian infants ${ }^{34}$. Other studies show similar associations between growth rate and iron status ${ }^{35,36}$.

Using a serum retinol cut-off value $<30 \mu \mathrm{g} \mathrm{dl}^{-1}$, as suggested by Sauberlich et $a l^{37}$, we found that $4.5 \%$ of the mothers had sub-clinical VAD with vitamin A levels in breast milk fat being low in $13.3 \%$ of mothers. These findings are similar to those of Rice et $a l .^{38}$, who found a threefold increase in prevalence of VAD in Bangladeshi women when comparing serum retinol (13\% VAD) versus breast milk vitamin A per gram of fat (46\% deficient) as indicators of vitamin A status.

Vitamin A deficiency is a public health concern in South Africa since a third of children aged 6-71 months were found to have sub-clinical VAD, with the prevalence found to be slightly lower (21\%) in the Western Cape 7 . In our group of younger infants, we found a lower proportion (10\%) of marginally VAD infants, most being under 3 months of age. A $10 \%$ prevalence of VAD indicates a moderate level of sub-clinical vitamin A deficiency? Although it is uncommon to find VAD in breast-fed infants under 6 months of age due to breast milk being a major source of vitamin A in an infant's diet ${ }^{39}$, infants within high-risk settings may be at risk for deficiency ${ }^{40,41}$. Again, few South African studies on vitamin A status have included young infants ( $<6$ months of age) as part of their cohort. Faber and Benade ${ }^{42}$ assessed the nutritional status of rural South African children aged 4 to 24 months and found that $37.3 \%$ had low vitamin A status even though $80 \%$ of the infants were still breast-fed. Wahed et al. ${ }^{40}$ found that $67 \%$ of Bangladeshi breast-fed infants under 6 months old were marginally VAD; other studies with similar populations confirm these findings in young infants 43

Our data did not indicate strong relationships between maternal and infant micronutrient levels, with the exception of MCV values and serum retinol concentrations. Studies have shown strong associations between maternal and infant micronutrient values ${ }^{25}$ as well as no associations $^{44}$.

Among the African population in South Africa, breastfeeding is a highly valued mode of infant feeding. However, in our entire sample of 117 infants there were no exclusively breast-fed infants. All infants were either predominantly breast-fed (22\%) or complementary breastfed (78\%). Significantly more infants were predominantly breast-fed under 3 months of age than over. However, the proportion of infants receiving complementary feeding was higher than predominant feeders, regardless of age category. Although breast milk contains a relatively low concentration of iron, the iron is highly bioavailable ${ }^{45}$, thus meeting the infant's needs up to 6 months of age. Nevertheless, iron stores decline as iron is mobilised to support infant growth ${ }^{46}$. Consequently, after 6 months of age, an exogenous source of iron is recommended for breast-fed infants. However, our data indicate that infants were deficient prior to 6 months of age. The lowest prevalence of anaemia was in the predominant breastfeeders (21\%), while within the complementary breast-fed group, the subgroups that included solid foods (S) tended to have higher levels of anaemia (37\% in BM $+\mathrm{S}$ and $41 \%$ in $\mathrm{BM}+\mathrm{S}+\mathrm{Subs}$ ). Although differences between feeding groups did not reach significance, our data are suggestive of the fact that early introduction of solid foods and other liquids to the breast-fed infant's intake may act as a contributing factor in the early onset of anaemia in these infants. Our speculation is supported by findings that show that breast milk iron is poorly absorbed once solids are added to the infant's diet ${ }^{47}$.

In summary, our study has provided much needed information on the nutritional status of peri-urban, lactating South African women and their infants under 6 months of age. Our findings indicate that $4.5 \%$ and $13.3 \%$ of the breast-feeding mothers had sub-clinical VAD, using serum and breast milk retinol concentrations, respectively. Close to a third of these mothers were found to be also anaemic, but few had very low haemoglobin values. More importantly, their breast-fed infants showed evidence of a high rate $(50 \%)$ of anaemia with a moderate level of subclinical VAD. It is surprising that such a large number of seemingly healthy infants exhibited low haemoglobin levels at a very young age (mean age 2.8 months). Micronutrient deficiencies continue to be a major public health concern; consequently, predictors of infant anaemia and VAD need to be clearly elucidated within these vulnerable settings. Since micronutrient deficiencies can occur very early in children's lives even when there is indication of good growth, we advocate larger prospective studies investigating the impact of infant feeding practices and other environmental determinants on the nutritional status of similar populations, including comparisons with exclusively breast-fed infants. Results of such proposed studies plus our findings can be used in evidenced-based planning of community-rooted interventions aimed at promoting optimal feeding practices.

\section{Acknowledgements}

The authors wish to thank Mrs Zola Bacela (fieldworker) and Mrs Virginia Mateza (nurse) for their valuable work during the study. Our gratitude is extended to participating mothers and their infants as well as the staff of Langa clinic; 
Drs Michael Hendricks and David Woods. We thank the Canadian International Development Agency for funding our study, and the Natural Sciences and Engineering Research Council of Canada for support awarded to Dr T Johns.

\section{References}

1 World Health Organization. Draft World Declaration on Nutrition. Theme Paper No. 6. In: Major Issues Nutrition Strategies, Proceedings of International Conference on Nutrition: Preventing Specific Nutrient Deficiencies. Rome: Food and Agricultural Organization, 1991; 2-40.

2 United Nations Children's Fund. State of the Worlds Children. New York: Oxford University Press, 1998.

3 De Benoist B. Iron-deficiency anemia: reexamining the nature and magnitude of the public health problem. Journal of Nutrition 2001; 131: 564S.

4 Lozoff B, Jimenez E, Wolfe A. Long-term developmental outcome of infants with iron deficiency. New England Journal of Medicine 1991; 325: 687-94.

5 Soewondo S, Husaini M, Politt E. Effects of iron deficiency on attention and learning processes in preschool children: Bandung, Indonesia. American Journal of Clinical Nutrition 1989; 50: 667-74.

6 Stoltzfus R. Defining iron-deficiency anemia in public health terms: a time for reflection. Journal of Nutrition 2001; 131: $565 S-7 S$.

7 South African Vitamin A Consultative Group. Anthropometric, vitamin A, iron and immunisation coverage status in children aged 6-71 months in South Africa. South African Medical Journal 1996; 86: 354-7.

8 Bhaskaram P. Micronutrient deficiencies in children - the problem and extent. Indian Journal of Pediatrics 1995; 62: $145-56$.

9 World Heath Organization (WHO)/United Nations Children's Fund. Indicators for Assessing Vitamin A Deficiency and Their Application in Monitoring and Evaluating Intervention Programmes. WHO/NUT/96.10. Geneva: WHO, 1996.

10 Kawakami H, Lönnerdal B. Isolation and function of a receptor for human lactoferrin in human fetal intestinal brush-border membranes. American Journal of Physiology 1991; 261: G841-6.

11 Chappell JE, Francis T, Clandinin MT. Vitamin A and E content of human milk at early stages of lactation. Early Human Development 1985; 11: 157-67.

12 Valquist A, Nilsson S. Mechanisms for vitamin A transfer from blood to milk in rhesus monkeys. Journal of Nutrition 1979; 109: 1456-63.

13 United Nations Children's Fund. UNICEF Global Database Breastfeeding Indicators [online], 2001. Available at http:// childinfo.org/eddb/brfeed/test/database.htm. Accessed May 2003

14 Richter LM. The Early Introduction of Solids: An Analysis of Belief and Practices among African Women in Soweto. Report. South Africa: University of the Witwatersrand, 1987.

15 Steyn NP, Badenhorst CJ, Nel JH. Breast feeding and weaning practices of Pedi mothers and the dietary intakes of their preschool children. South African Journal of Food Sciences and Nutrition 1993; 5: 10-3.

16 Zollner E, Carlier ND. Breast feeding and weaning practices in Venda. South African Medical Journal 1993; 83: 580-3.

17 Ross SM, Van Middelkoop A, Khoza NC. Breastfeeding practices in a black community. South African Medical Journal 1983; 63: 23-5.

18 Statistics South Africa. Census Data from Urban Policy Unit. Pretoria: Statistics South Africa, 1996.
19 Catignani GL, Bieri JG. Simultaneous determination of retinol and $\alpha$-tocopherol in serum or plasma by liquid chromatography. Clinical Chemistry 1983; 29: 708-12.

20 Lucas A, Gibbs JA, Lyster RL, Baum JD. Creamatocrit: simple clinical technique for estimating fat concentration and energy value of human milk. British Medical Journal 1978; 1: $1018-20$.

21 Strobel M, Heinrich F, Biesalski HK. Improved method for rapid determination of vitamin A in small samples of breast milk by HPLC. Journal of Chromatography 2000; 898: 179-83.

22 World Health Organization (WHO). Contemporary Patterns of Breastfeeding. Report on the WHO Collaborative Study on Breastfeeding. Geneva: WHO, 1981; 165-211.

23 World Health Organization (WHO). Indicators for Assessing Breastfeeding Practices. Update No. 10 Geneva: WHO, 1997.

24 Bourne LT, Langenhoven ML, Steyn K, Jooste PL, Laubscher JA, Bourne DE. Nutritional status of 3-6 year old African children in the Cape Peninsula. East African Medical Journal 1994; 71: 695-702.

25 Dijkhuizen MA, Wieringa FT, West CE, Muherdiyantiningsih Mulilal. Concurrent micronutrient deficiencies in lactating mothers and their infants in Indonesia. American Journal of Clinical Nutrition 2001; 73: 786-91.

26 Stoltzfus RJ, Dreyfuss ML. Guidelines for the Use of Iron Supplements to Prevent and Treat Iron Deficiency Anemia. Washington, DC: ILSI Press, 1998; 1-39.

27 United Nations Children's Fund/World Health Organization (WHO). Prevention and Control of Iron Deficiency Anemia in Women and Children. Geneva: WHO, 1999.

28 World Health Organization (WHO). Indicators and Strategies for Iron Deficiency and Anemia Programmes. Report of the WHO/UNICEF/UNU Consultation. Geneva: WHO, 1993.

29 Domellof M, Dewey KG, Lonnerdal B, Cohen RJ, Hernell O. The diagnostic criteria for iron deficiency in infants should be reevaluated. Journal of Nutrition 2002; 132: 3680-6.

30 Kirsten GF, Heese HD, Villiers S, Dempster WS, Varkevisser HE, Hoffman M. The prevalence of iron deficiency in apparently healthy Cape coloured infants. South African Medical Journal 1984; 65: 378-80.

31 Grajeda R, Pérez-Escamilla R, Dewey KG. Delayed clamping of the umbilical cord improves hematologic status of Guatemalan infants at 2 mo of age. American Journal of Clinical Nutrition 1997; 65: 425-31.

32 Geethanath RM, Ramji S, Thirupuram S, Rao YN. Effect of timing of cord clamping on the iron status of infants at 3 months. Indian Pediatrics 1997; 34: 103-6.

33 Halvorsen S. Iron balance between mother and infant during pregnancy and breastfeeding. Acta Paediatrica 2000; 89: $625-7$.

34 Lartey A, Manu A, Brown KH, Dewey KG. Predictors of micronutrient status among six- to twelve-month-old breastfed Ghanaian infants. Journal of Nutrition 2000; 130: 199-207.

35 Michaelsen KF, Milman N, Samuelson G. A longitudinal study of iron status in healthy Danish infants: effects of early iron status, growth velocity and dietary factors. Acta Paediatrica 1995; 84: 1035-44.

36 Willows ND, Morel J, Gray-Donald K. Prevalence of anemia among James Bay Cree infants of northern Quebec. Canadian Medical Association Journal 2000; 162: 323-6.

37 Sauberlich HE, Hodges RE, Wallace DL, Kolder H, Canham $\mathrm{JE}$, Hood J, et al. Vitamin A metabolism and requirements in the human studied with the use of labeled retinol. Vitamins E Hormones 1974; 32: 251-75.

38 Rice AL, Stoltzfus RJ, de Francisco A, Kjolhede CL. Evaluation of serum retinol, the modified-relative-dose-response ratio, and breast-milk vitamin $\mathrm{A}$ as indicators of response to 
postpartum maternal vitamin A supplementation. American Journal of Clinical Nutrition 2000; 71: 799-806.

39 Newman V. Vitamin A and breast-feeding: a comparison of data from developed and developing countries. Food and Nutrition Bulletin 1994; 15: 161-76.

40 Wahed MA, Alverez JO, Rahman MM. Subclinical vitamin A deficiency in young infants from Bangladesh. Nutrition Research 1997; 17: 591-8.

41 Stoltzfus RJ, Underwood BA. Breast-milk vitamin A as an indicator of the vitamin A status of women and infants. Bulletin of the World Health Organization 1995; 73: 703-11.

42 Faber M, Benade AJ. Nutritional status and dietary practices of 4-24 months old children from a rural South African community. Public Health Nutrition 1999; 2: 179-85.

43 Mahalanabis D. Breast feeding and vitamin A deficiency among children attending a diarrhoea treatment centre in
Bangladesh: a case-control study. British Medical Journal 1991; 303: 493-6.

44 Okolo SN, Onwuanaku C, Okonji M, Vanderjagt DJ, Milson $\mathrm{M}$, Churchwell C, et al. Concentration of eight trace minerals in milk and sera of mother-infant pairs in Northern Nigeria. Journal of Tropical Pediatrics 2000; 46: 160-2.

45 Saarinen UM, Siimes MA, Dallman PR. Iron absorption in infants: high bio-availability of breast milk iron as indicated by the extrinsic tag method of iron absorption and by the concentration of serum ferritin. Journal of Pediatrics 1977; 91: 36-9.

46 Dallman PR, Siimes MA, Stekel A. Iron deficiency in infancy and childhood. American Journal of Clinical Nutrition 1980; 33: $86-118$

47 Oski FA, Landaw SA. Inhibition of iron absorption from human milk by baby food. American Journal of Diseases of Children 1980; 134: 459-60. 